\title{
Osteogenic potential of periodontal ligament stem cells are unaffected after exposure to lipopolysaccharides
}

\author{
Mayra Laino ALBIERO(a) \\ Bruna Rabelo AMORIM(a) \\ Márcio Zaffalon CASATI(a) \\ Enilson Antonio SALLUM(a) \\ Francisco Humberto NOCITI \\ JUNIOR ${ }^{(a)}$ \\ Karina Gonzales SILVÉRIO(a) \\ (a) Universidadade de Campinas - UNICAMP, \\ Piracicaba Dental School, Department of \\ Prosthodontics and Periodontics, Piracicaba, \\ São Paulo, Brazil.
}

Declaration of Interests: The authors certify that they have no commercial or associative interest that represents a conflict of interest in connection with the manuscript.

Corresponding Author: Karina Gonzales Silvério Email:kgsilverio@fop.unicamp.br

http://doi.org/10.1590/1807-3107BOR-2017.vol31.0017

Submitted: July 01, 2016

Accepted for publication: Nov 21, 2016

Last revision: Dec 09, 2016

\begin{abstract}
Periodontitis develops as a result of a continuous interaction between host cells and subgingival pathogenic bacteria. The periodontium has a limited capacity for regeneration, probably due to changes in periodontal ligament stem cells (PDLSCs) phenotype. The aim of this study was to evaluate the effects of lipopolysaccharides from Porphyromonas gingivalis (PgLPS) on mesenchymal phenotype and osteoblast/cementoblast $(\mathrm{O} / \mathrm{C})$ potential of PDLSCs. PDLSCs were assessed for Toll-like receptor 2 (TLR2) expression by immunostaining technique. After, cells were exposed to PgLPS, and the following assays were carried out: (i) cell metabolic activity using MTS; (ii) gene expression for $I L-1 \beta, T N F-\alpha$ and OCT-4 by real-time polymerase chain reaction (RT-qPCR); (iii) flow cytometry for STRO-1 and CD105, and (iv) osteogenic differentiation. PDLSCs were positive for TLR2. PgLPS promoted cell proliferation, produced IL-1 $\beta$ and TNF- $\alpha$, and did not affect the expression of stem cell markers, STRO-1, CD105 and OCT-4. Under osteogenic condition, PDLSCs exposed to PgLPS showed a similar potential to differentiate toward osteoblast/cementoblast phenotype compared to control group as revealed by mineralized matrix deposition and levels of transcripts for RUNX2, ALP and OCN. These results provide evidence that PgLPS induces pro-inflammatory cytokines, but does not change the mesenchymal phenotype and osteoblast/cementoblast differentiation potential of PDLSCs.
\end{abstract}

Keywords: Lipopolysaccharides; Periodontal Ligament; Stem Cells, Osteoblasts.

\section{Introduction}

Periodontal disease develops as a result of a continuous interaction between host cells and subgingival pathogenic bacteria, such as the gram-negative anaerobe Porphyromonas gingivalis (Pg), a major etiological agent of periodontitis. ${ }^{1}$ Once damaged, the periodontium has a limited capacity for regeneration, which is an extremely complex process, mostly resulting in repair rather than regeneration during the healing process.

Currently, a wide variety of regenerative therapies have been proposed to promote the regeneration of periodontal supporting tissues, relying almost entirely on the use of implantation of structural substitutes and focusing specially on regenerating lost alveolar bone. However, the 
clinical results are hard to predict, and histologically, the regenerative potential of these techniques has proved limited. ${ }^{2}$

The complex series of events associated with periodontal regeneration involves recruitment of locally derived progenitor cells to the affected site, and their subsequent differentiation into periodontal ligament and mineralized tissues. ${ }^{3}$ The limited regeneration potential of current techniques may be a result of poor innate ability of damaged periodontal tissues to regenerate. ${ }^{4}$ This may occur after the prolonged inflammatory process caused by pathogenic bacteria. Periodontopathic bacteria possess a number of potential virulence factors and induce host inflammatory mediators, eventually leading to connective tissue degradation and alveolar bone resorption. ${ }^{5}$

Studies have shown that the presence of chronic inflammation might compromise the migration, proliferation and availability of stem cells in multiple sclerosis ${ }^{6}$ and atherosclerosis. ${ }^{7}$ Regarding periodontal disease, an in vitro study showed that exposure to the etiological factors induced apoptosis in periodontal ligament cells. ${ }^{8}$

P. gingivalis presents several bioactive components. Lipopolysaccharide (LPS) is a major constituent of the bacteria outer membrane, and is considered a potential inducer of pro- and anti-inflammatory cytokines and chemokines. ${ }^{9}$ These proteins interact with Toll-like receptors (TLRs), which play key roles in innate immune recognition and cellular activation in response to pathogens. ${ }^{1}$ Among these receptors, TLR2 and TLR4 function as main sensors for innate cell wall components of gram-negative bacteria, and may be related in the progression of periodontitis. ${ }^{1,10}$

Based on current available evidence, exposure to an enriched endotoxin environment may affect mesenchymal stem cell (MSC) properties such as self-renewal, differentiation potential, and production of cytokines and extracellular matrix compounds. Thus, this study investigated the effects of lipopolysaccharides from Porphyromonas gingivalis (PgLPS) on cell metabolic activity, expression of pro-inflammatory cytokines and stem cell markers, and osteoblast/cementoblast differentiation potential of periodontal ligament stem cells (PDLSCs).

\section{Methodology}

\section{Cell culture}

This study was approved by the Institutional Review Board of Piracicaba Dental School - University of Campinas (\#022/2011). Three populations of mesenchymal progenitor cells $\left(\mathrm{STRO1}^{+}, \mathrm{CD} 105^{+}, \mathrm{CD} 34\right.$, and CD45- cells) from periodontal ligament (PDL) of permanent teeth were obtained and characterized in a previous study. ${ }^{11}$ Briefly, $\mathrm{CD} 105^{+}$-enriched cell subsets from PDL were isolated by magnetic cell sorting, and characterized by flow cytometry and immunostaining. All three PDLSC populations were cultured in Dulbecco's modified Eagle's minimal essential medium (DMEM) supplemented with $10 \%$ fetal bovine serum, $1 \%$ L glutamine and $1 \%$ penicillin/streptomycin (GIBCO BRL, Life Technologies, Carlsbad, USA) (standard media) at $37^{\circ} \mathrm{C}$ in atmosphere containing $5 \% \mathrm{CO}_{2}$, frozen with Recovery ${ }^{\mathrm{TM}}$ Cell Culture Freezing Medium (Gibco BRL) and kept in liquid nitrogen for subsequent experiments.

\section{Preparation of LPS solution from Porphyromonas gingivalis}

Bacterial LPS was suspended in $1 \mathrm{~mL}$ of pure, sterile and endotoxin-free water as a stock solution (concentration $1 \mathrm{mg} / \mathrm{mL}$ ) of Porphyromonas gingivalis (InvivoGen, San Diego, USA). At the time of each experiment, the concentrations of $0,0.1,1$ and $10 \mu \mathrm{g} / \mathrm{mL}^{12}$ were obtained by diluting LPS in DMEM from the stock solution.

\section{Immunostaining for TLR2}

To evaluate the expression pattern of TLR2, PDLSCs were seeded at $4 \times 10^{4}$ cells/well on glass coverslips (13 mm, Knittel ${ }^{\circledR} \mathrm{GmbH}$ - Braunschweig, Germany) placed in 24-well plates (Falcon, BD Labware, Franklin Lakes, USA), and cultured for 24 hours in standard media. Afterward, cells were fixed in $4 \%$ paraformaldehyde for 10 minutes, blocked with $3 \%$ bovine serum albumin (BSA, Sigma, St Louis, USA) for 30 minutes, followed by a standard protocol for immunostaining. Cells were incubated with a mouse anti-human TLR2 antibody (1:50; Abcam, Cambridge, USA) followed by a secondary antibody Goat anti-mouse IgG Alexa Fluor 488 (1:1000) (Invitrogen, Carlsbad, USA) for one hour. Samples were 
counterstained with TO-PRO ${ }^{\circledR}-3$ iodide 642/661 (1:2000) (Invitrogen) for 15 minutes. For negative control, only secondary antibody was used. The samples were analyzed by confocal laser scanning microscopy (Leica TCS SP5AOBS, Mannheim, Germany).

\section{Cell metabolic activity assay}

To determine the cytotoxicity of $0,0.1,1$ or $10 \mu \mathrm{g} / \mathrm{mL}$ concentrations of PgLPS, MTS assay was carried out as described previously. ${ }^{13}$ At time points of 1, 3, 7, and 10 days, cells were washed with phosphate buffered saline (GIBCO BRL). Then, $20 \mu \mathrm{L}$ of CellTiter $96^{\circledR} \mathrm{AQ} \mathrm{Q}_{\text {ueous }}$ One Solution Reagent-MTS assay (PromegaCo., Ltd. Madison, USA) was added to each well and cells were incubated for 2 hours. Absorbance at 490nm was measured.

\section{Pro-inflammatory cytokine gene expression}

To verify whether PDLSCs responded to $0,0.1,1$ or $10 \mu \mathrm{g} / \mathrm{mL}$ of PgLPS, a real time quantitative polymerase chain reaction (RT-qPCR) was performed to assess gene expression changes on pro-inflammatory cytokines interleukin-1 beta $(I L-1 \beta)$ and tumor necrosis factor alpha $(T N F-\alpha)$. PDLSCs were seeded $\left(2 \times 10^{5} / 60-\mathrm{mm}\right.$ dishes) and cultured in standard media for 24 hours. Subsequently, media was changed and supplemented with PgLPS. After 24 hours, total RNA was obtained using TRIzol ${ }^{\circledR}$ reagent (Invitrogen) and mRNA levels were determined by RT-qPCR.

\section{Mesenchymal stem cell markers expression}

\section{Flow cytometry analysis of cell surface}

Fluorescence-active cell sorting was used to evaluate the expression of cell surface markers STRO-1 and CD105 (Endoglin, SH2 antigen) under PgLPS exposure. PDLSCs were plated in $100-\mathrm{mm}$ tissue culture dishes and cultured in standard media for 24 hours. Subsequently, media was changed to $10 \%$ DMEM supplemented with $1 \mu \mathrm{g} / \mathrm{mL}$ PgLPS. After 7 days, cell suspension was obtained by detaching monolayers of PDLSC populations with $5 \mathrm{mg} / \mathrm{mL}$ of Collagenase IV (Gibco) and 5mM EDTA (Applied Biosystems, Foster City, USA), and blocking with 10\% normal donkey serum (Sigma) for 20 minutes. Cells $\left(10^{6}\right)$ were incubated with mouse anti-human monoclonal antibodies against STRO-1-fluorescein isothiocyanate (FITC) (BioLegend, San Diego, USA) and CD105-allophycocianin (APC) (BD Bioscience, San Jose, USA) for 40 minutes at $4^{\circ} \mathrm{C}$, washed and resuspended in phosphate buffered saline ( $\mathrm{pH} 7,4)$. As a negative control, FITC and APC-conjugated non-specific mouse IgG1 antibodies (BD Bioscience) were used. Quantitative fluorescence-activated cell sorter (FACS) analysis was performed on a FACScan instrument (BD FACSCalibur ${ }^{\mathrm{TM}}$; BD Bioscience Pharmigen, San Jose, USA), and the results were processed using CELLQUEST software (BD Bioscience Pharmigen).

\section{OCT-4 gene expression}

To determine whether LPS exposure could change the gene expression of octamer-binding transcription factor 4 (OCT-4), PDLSCs were cultured in standard media supplemented with $1 \mu \mathrm{g} / \mathrm{mL}$ PgLPS. After 7 days, total RNA was obtained using TRIzol ${ }^{\circledR}$ reagent (Invitrogen) and the mRNA levels for OCT-4 were determined by RT-qPCR.

\section{Osteogenic induction}

To evaluate the ability of PDLSCs to differentiate along the osteoblast/cementoblast lineage under PgLPS exposure, cells were seeded with standard media for gene expression ( $2 \times 10^{5} / 60-\mathrm{mm}$ dishes $)$ and mineral nodule formation (24-well plates) in vitro. After 24 hours, it was added osteogenic-inducing medium (OM) (DMEM 10\% FBS, $50 \mu \mathrm{g} / \mathrm{mL}$ ascorbic acid, $10 \mathrm{mM} \beta$-glycerol-phosphate, $10^{-5} \mathrm{M}$ dexamethasone) supplemented or not with $1 \mu \mathrm{g} / \mathrm{mL}$ PgLPS. Total RNA was obtained using TRIzol ${ }^{\circledR}$ reagent (Invitrogen) at days 3,7 , and 14 , followed by the expression analysis of run-related transcription factor-2 (RUNX2), alkaline phosphatase $(A L P)$ and osteocalcin $(O C N)$. In parallel, in vitro mineral nodule formation was assessed at day 21 using the Alizarin Red staining (AR-S, Sigma). ${ }^{13}$

\section{Gene expression analysis}

Transcription expression of cytokines $I L-1 \beta$ and TNF- $\alpha$; osteogenic markers RUNX2, ALP and OCN; and OCT 4 were examined by RT-qPCR. Samples were prepared as described previously ${ }^{(13)}$. Primers sequences for ALP, OCN, RUNX2, IL-1 $\beta$, TNF- $\alpha$, OCT-4 and glyceral-dehyde-3-phosphate dehydrogenase $(G A P D H)$ are shown in Table 1. 


\section{Statistical analysis}

All experiments were performed in triplicate. Means and standard deviations were obtained to establish statistical comparisons. To assess cell proliferation, OCT-4 and osteoblast gene expression, a two-way Analysis of Variance test was performed, followed by Tukey test. To assess the effect of LPS on cytokines' gene expression non-parametric Kruskal-Wallis test was performed followed by the Student-Newman-Keuls test, using Bioestat 5.0 software (Belém, Brazil). $P$ values less than 0.05 were considered significant.

\section{Results}

\section{PDLSCs express PgLPS receptor}

Immunofluorescence analysis revealed that PDLSCs exhibited positive staining for TLR2, confirming that these cells are capable of recognizing PgLPS (Figures $1 \mathrm{~A}$ and $\mathrm{B}$ ).

\section{PgLPS partially induces PDLSCs response}

To verify whether PDLSCs responded to PgLPS, a metabolic activity, as an indicator for cell proliferation, was measured using MTS assay. All cell populations

Table 1. Primer sequences used for PCR amplification in real time-PCR.

\begin{tabular}{lccc}
\hline Gene & Forward Primer & Reverse Primer & Amplicon \\
\hline ALP & $5^{\prime}$-cgggcaccatgaaggaaa-3' & $5^{\prime}$-ggccagaccaaagatagagtt-3' & 184 \\
OCN & $5^{\prime}$-agctcaatccggactgt-3' & $5^{\prime}$-ggaagaggaaagaagggtgc-3' & 150 \\
RUNX2 & $5^{\prime}$-ccgtccatccactctaccac-3' & $5^{\prime}$-atgaaatgcttgggaactgc-3' & 139 \\
IL-1 $\beta$ & $5^{\prime}$-cttcttcgacacatgggataac-3' & $5^{\prime}$-tttgggatctacactctccagc-3' & 283 \\
TNF- $\alpha$ & $5^{\prime}$-tccacccatgtactcctcac-3' & $5^{\prime}$-cctcccagatagatgggctcata-3' & 155 \\
OCT-4 & $5^{\prime}$-agcttagcttcaagaacatgtgta -3' & $5^{\prime}$-gttgcctctcactcggt-3' & 161 \\
GAPDH & $5^{\prime}$-acatcatccctgcctctac-3' & $5^{\prime}$-ccaccttcttgatgtcatcatatttg-3' & 171 \\
\hline
\end{tabular}

ALP: alkaline phosphatase; OCN: osteocalcin; RUNX2: runt-related transcription factor 2; IL-1 $\beta$ : interleukin-1 beta; TNF- $\alpha$ : tumor necrosis factor alpha; OCT-4: octamer-binding transcription factor 4; GAPDH, glyceraldehyde-3-phosphate dehydrogenase.
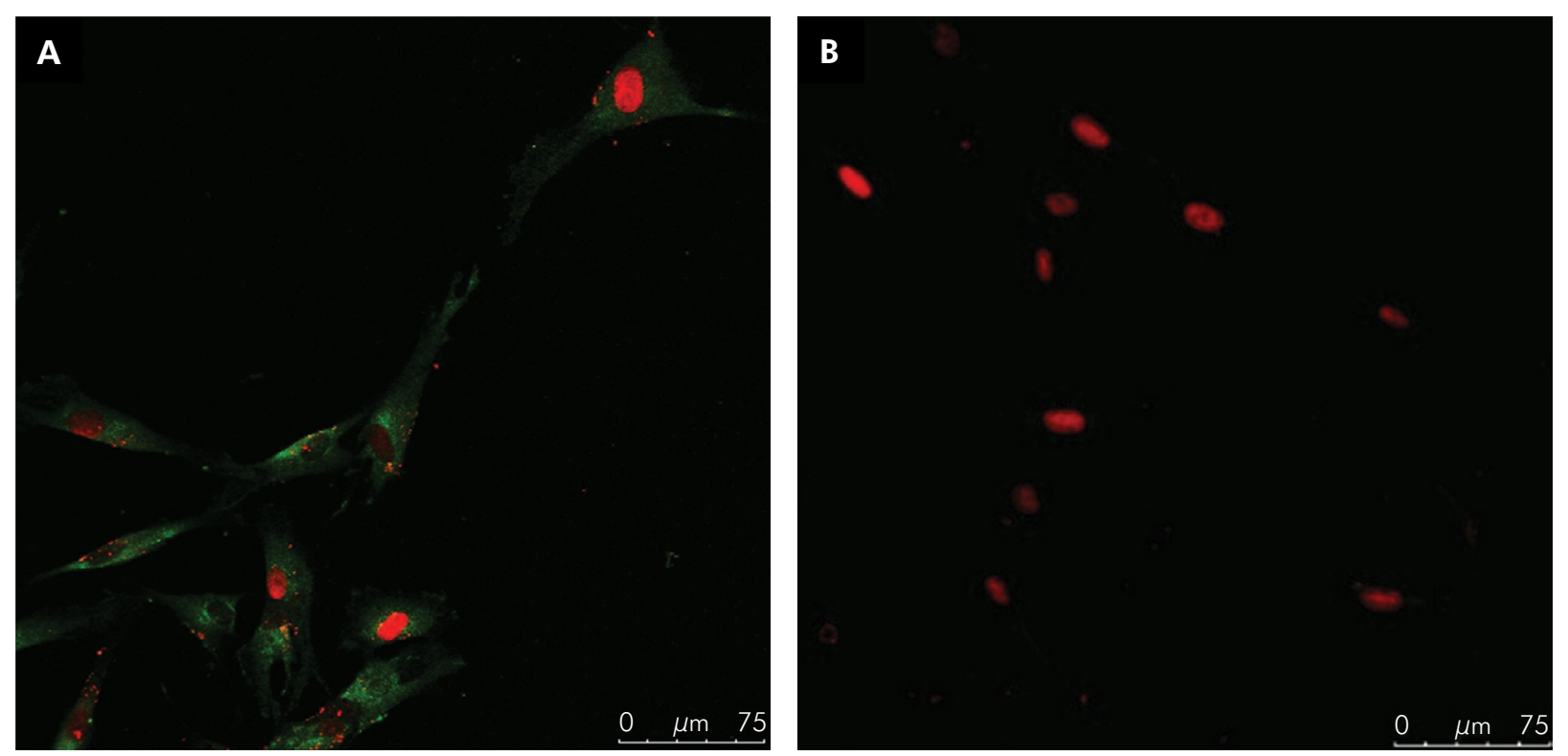

Figure 1. Periodontal ligament progenitor cells express TLR2. (A) Positive immunofluorescence for the TLR2. (B) Control is represented by PDLSCs incubated with secondary antibody only. 
were able to retain the capacity to form adherent colonies and spindle-shaped fibroblasts after exposure to PgLPS (data not shown). As shown in Figure 2A, LPS did not affect the proliferation of PDLSCs during the 10-day period, even after incubation with a relatively high concentration of toxin $(1 \mu \mathrm{g}$ and $10 \mu \mathrm{g} / \mathrm{mL})$. In addition, MTS values showed a time-dependent increase of cell proliferation for all groups, with an increasing number of cells between 1 and 7 days in culture, stabilizing after 7 days.

Gene expression changes on pro-inflammatory cytokines showed that PDLSCs only expressed $I L-1 \beta$ and TNF- $\alpha$ mRNA after PgLPS challenge. The expression of TNF- $\alpha$ was upregulated for all PgLPS concentrations, however only at a concentration of $1 \mu \mathrm{g} / \mathrm{mL}$ a significant difference was found compared to non-exposed cells $(\mathrm{p}<0.05)$ (Figure 2B). Even with increased IL-1 $\beta$ transcripts after 24 hours of LPS challenge, the difference was not significant between groups, probably due to the greater variability of $I L-1 \beta$ expression among the three cell populations (Figure 2C).

\section{Neither OCT-4, STRO-1 or CD105 are influenced by PgLPS exposure}

Since the results showed that $T N F-\alpha$ was upregulated at a concentration of $1 \mu \mathrm{g} / \mathrm{mL}(\mathrm{p}<0.05)$, this concentration was chosen to proceed with subsequent experiments. First, the possible role of PgLPS on the MSC phenotype was investigated. Flow cytometry analysis showed that the proportion of STRO- $1^{+}$and $\mathrm{CD} 105^{+}$cells remain unaffected after exposure to PgLPS for 7 days (Table 2). In addition, gene expression analysis by qRT-PCR revealed similar mRNA levels of the pluripotent stem cell marker OCT-4 for exposed and non-exposed cells (Figure 3A).

\section{PgLPS challenge does not change osteoblast/cementoblast differentiation of PDLSCs}

PDLSCs exposed and non-exposed to PgLPS were induced to differentiate into osteoblast/cementoblast phenotype for 21 days. Both groups were able to promote mineral nodule deposition in vitro, as visualized by AR-S (Figure 3B). No mineralized nodules were observed in cells cultured in the DMEM used as a
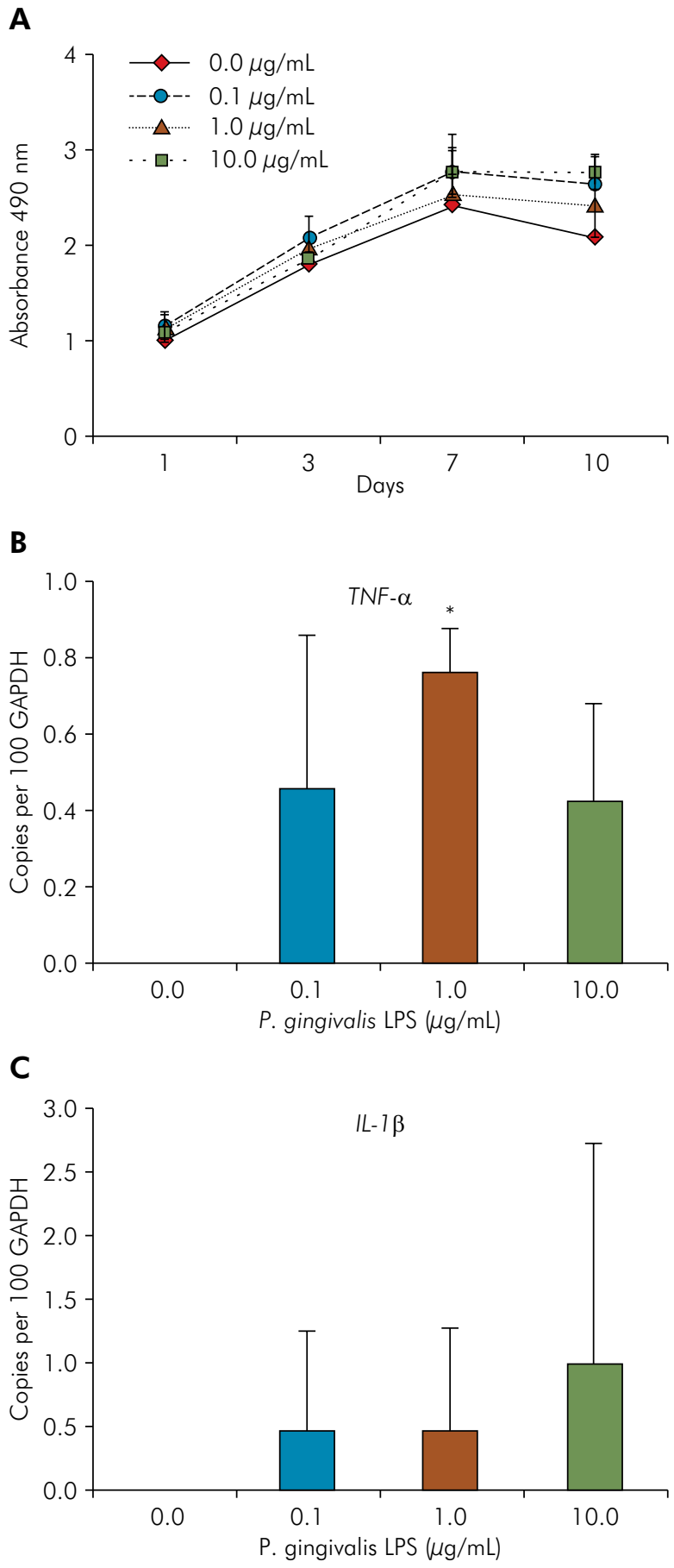

Figure 2. $P$. gingivalis lipopolysaccharides (PgLPS) effect on metabolic activity and cytokines expression. (A) Periodontal ligament stem cells (PDLSCs) were cultured in the presence of PgLPS at concentrations of $0,0.1,1$ and $10 \mu \mathrm{g} / \mathrm{mL}$. Metabolic activity as an indicator for cell proliferation was measured with MTS assay at 1, 3, 7 and 10 days. (B and C) RT-qPCR showed that PgLPS enhanced the expression of $I L-1 \beta$ and TNF- $\alpha$, respectively, in PDLSCs after 24 hours of exposure. Representative data of three independent experiments are shown. ${ }^{*}$ Statistical significance intergroup ( $\left.<<0.05\right)$. 
- Osteogenic potential of periodontal ligament stem cells are unaffected after exposure to lipopolysaccharides

Table 2. Percentage of STRO- $1^{+}$and $\mathrm{CD} 105^{+}$cells in the periodontal ligament stem cells populations after $P$. gingivalis lipopolysaccharide $(1 \mu \mathrm{g} / \mathrm{mL})$ challenge.

\begin{tabular}{|c|c|c|c|c|}
\hline \multirow{2}{*}{ PDL-CD105+ populations } & \multicolumn{2}{|c|}{ STRO- 1} & \multicolumn{2}{|c|}{ CD105 } \\
\hline & control & PgLPS & control & PgLPS \\
\hline 1 & 0.47 & 0.5 & 97.67 & 95.94 \\
\hline 2 & 1.67 & 0 & 98.58 & 94.68 \\
\hline 3 & 1.1 & 1.65 & 94.52 & 75.22 \\
\hline Mean \pm SD & $1.08 \pm 0.6$ & $0.71 \pm 0.84$ & $96.92 \pm 2.13$ & $88.61 \pm 11.61$ \\
\hline
\end{tabular}

PgLPS: Porphyromonas gingivalis.

A

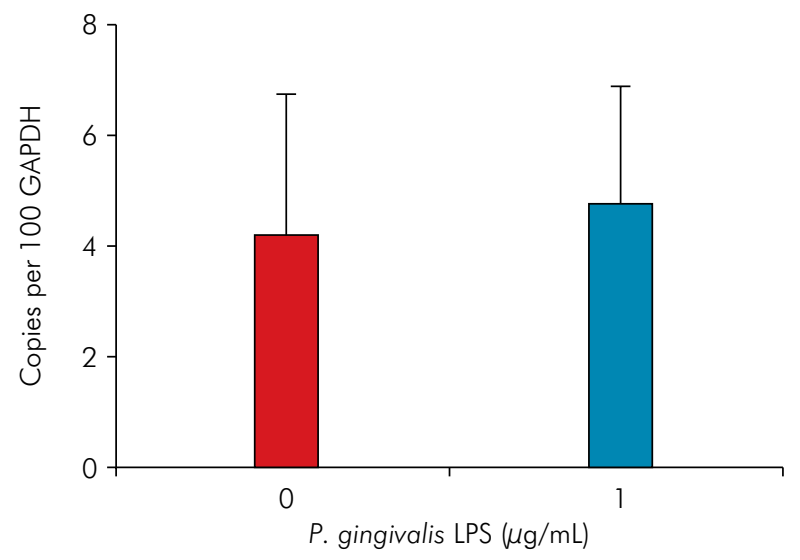

B
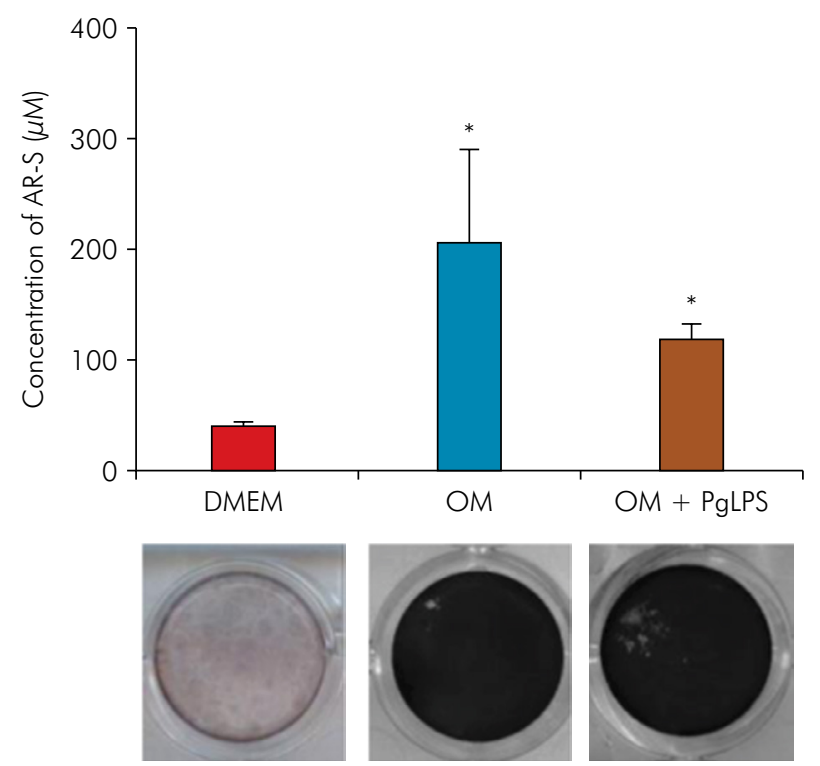

C

RUNX2
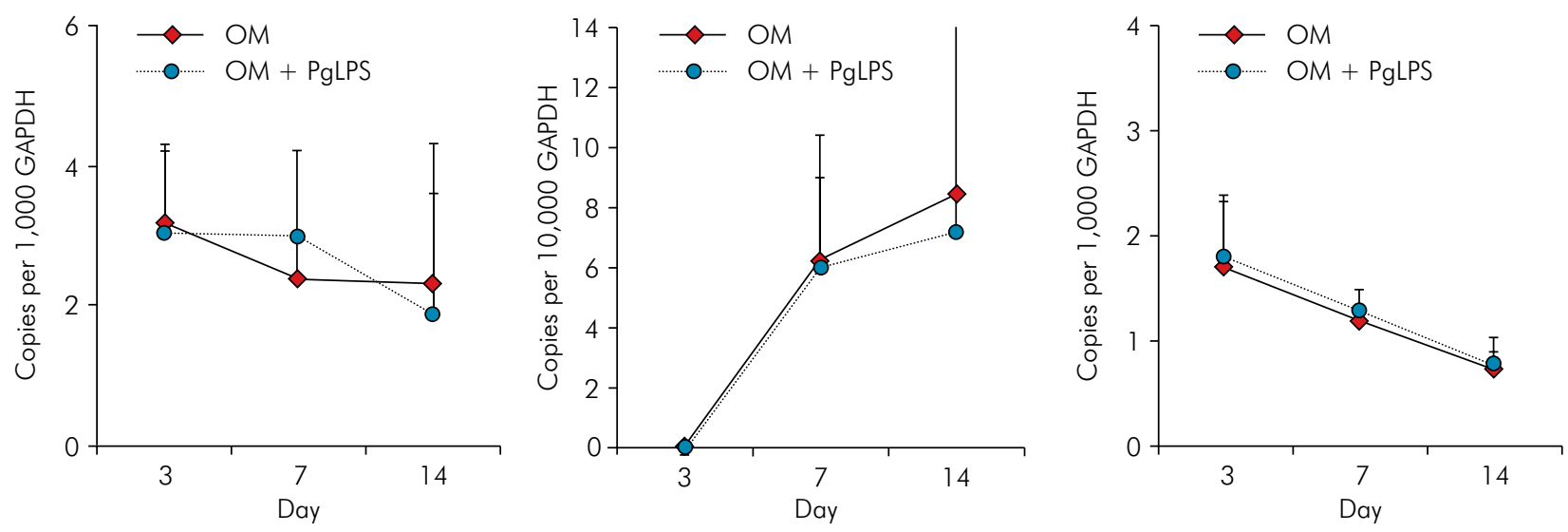

Figure 3. Stem cell markers expression and osteoblast/cementoblast differentiation of periodontal ligament stem cells (PDLSCs) after P. gingivalis lipopolysaccharides (PgLPS) exposure. (A) Gene expression for OCT-4 after 24 hours of $1 \mu \mathrm{g} / \mathrm{mL}$ PgLPS exposure. (B) Quantification of AR-S showed that $1 \mu \mathrm{g} / \mathrm{mL}$ PgLPS did not affect PDLSCs mineralization at 21 days. (C) PDLSCs were cultured in Osteogenic-inducing media $(\mathrm{OM})$, or OM $+1 \mu \mathrm{g} / \mathrm{mL}$ PgLPS for 3, 7 and 10 days. RT-qPCR analysis indicated that PgLPS did not alter the expression pattern of mRNAs for RUNX2, ALP and OCN. Representative data of three independent experiments are shown. * Statistical significance intergroup $(p<0.05)$. 
control. The potential for osteoblast/cementoblast differentiation was further confirmed by qRT-PCR analysis, showing an increased expression of a key osteoblast transcription factor, RUNX2, and two osteoblast-specific early/late differentiation transcripts (ALP and $O C N$, respectively) in osteogenically-induced cells compared to non-induced (Figure 3C). When cells were cultured in OM supplemented with PgLPS, levels of transcripts for RUNX2, ALP, and OCN showed a similar behavior compared to the positive control group, in all studied periods (Figure 3C).

\section{Discussion}

MSCs play an important role on periodontal regeneration, so understanding the factors and mechanisms modulating their regenerative capacity is important to increase treatment predictability. ${ }^{14}$ Some studies suggest that periodontal ligament cells may alter their phenotype in response to inflammation promoted by bacterial lipopolysaccharides. ${ }^{15,16,17}$ Porphyromonas gingivalis is known to produce a repertoire of virulence factors such as fimbriae, capsules, LPS, lipoteichoic acids, hemagglutinins, gingipains, outer membrane proteins and vesicles. ${ }^{1}$ Lipopolysaccharide is one of the most abundant virulence factors from $P$. gingivalis, as it activates the host inflammatory response and disrupts bone remodeling process. ${ }^{1,18}$ Since the effect of PgLPS on PDLSCs remains unknown, the aim of the present study was to investigate whether this virulence factor would affect the biological properties of PDL progenitor cells. PDL heterogeneous cell population was purified to CD105 surface marker, the most frequently reported positive surface marker in MSCs. ${ }^{19}$. The PDL progenitor cell populations were previously characterized by our group as being pluripotent mesenchymal progenitor cells by expression of stem cell markers such as CD105, CD166, OCT-4, and STRO-1. ${ }^{11}$

Studies have shown that the TLRs family is involved in the recognition of bacterial cell wall components ${ }^{20}$ and a current study described that PgLPS triggers an inflammatory response by binding to TLR2 and TLR4. ${ }^{10}$ In the present study, TLR2 expression in PDLSC populations was verified, emphasizing that these cells can recognize bacterial virulence factors. Furthermore, a previous study published by our research group reported the expression of TLR4 in these same cell populations. ${ }^{13}$ To our knowledge, this is the first study to describe the expression of these receptors by PDL $\mathrm{CD} 105^{+}$progenitor cells, although previous studies have reported the expression of TLR4 in cementoblasts, ${ }^{15}$ and of TLR2 and TLR4 in the heterogeneous PDL cell population..$^{9,21}$

To evaluate the cytotoxicity effect of PgLPS, PDLSCs were initially cultured in the presence of different concentrations of this bacterial toxin. The data obtained in this study indicate that cells remained viable and proliferating regardless of the PgLPS concentration. The presence of the active proliferation stage was also found in studies that assessed the effect of $P$. gingivalis endotoxin in pre-osteoblastic, ${ }^{22}$ PDL, ${ }^{23}$ and PDLSC cells. ${ }^{18}$

Cytokines' gene expression was then performed to determine PgLPS effect on cell inflammatory response. Two pro-inflammatory cytokines that affect bone formation, ${ }^{24} T N F-\alpha$ and $I L-1 \beta$, were investigated. As observed in PDL cells, ${ }^{9,23,25}$ PDLSCs, ${ }^{25}$ and human monocytic cells, ${ }^{26}$ our cell populations showed an increase of transcripts for TNF- $\alpha$ and $I L-1 \beta$ after PgLPS exposure. These results suggest that PDL progenitor cells present a pro-inflammatory response to stimulation by $P$. gingivalis similar to the active immune cells.

Although PDLSCs have shown a pro-inflammatory response after exposure to the bacterial toxins, there is no evidence about the effect of bacterial challenge on the stem cell phenotype. The findings of the present study demonstrated that the percentage of CD105+ cells remained high in PDLSCs population even in the presence of PgLPS. Another important stem cell marker, STRO-1, was also evaluated. Flow cytometry analysis revealed that, on average $1.08 \%$ of PDLSCs were STRO-1 $1^{+}$. This low expression of STRO-1 is in agreement with other reports in PDLSCs, ${ }^{27}$ PDL cells, ${ }^{28}$ dental pulp and dental follicle stem cells. ${ }^{29}$ After exposure to bacterial toxin, on average $0.71 \%$ of PDLSCs remained positive for STRO-1. Stem cell markers expression showed that there was no significant difference in exposed versus non-exposed cells, however it is important to highlight the distinct 
behavior of each PDLSC population. As shown by our data, PDLSC population \#3 presented a lower positivity for CD105 and STRO-1 after LPS challenge. On the other hand, the positivity of both stem cell markers remained unaffected in the population \#1.

The multipotential capability of PDLSCs may also be associated with the expression of OCT-4. As observed in dental pulp MSCs, ${ }^{30}$ our findings revealed that the endotoxin challenge did not affect OCT-4 mRNA levels in PDL progenitor cells. To the best of our knowledge, the present study is the first to assess the expression of stem cell-related markers (CD105, STRO-1 and OCT-4) in PDLSCs after bacterial endotoxin challenge. The findings that stem cell markers expression are not affected in the presence of $P$. gingivalis LPS, raises the possibility that even under an inflammatory condition, periodontal ligament MSCs are capable of maintaining their pluripotential and undifferentiated state.

MSCs are also characterized by the capacity of differentiating into multiple types of skeletal tissues. ${ }^{31,32}$ As periodontal regeneration requires formation of new bone and cementum, it is important to understand the osteoblastic/cementoblastic differentiation pattern of PDLSCs challenged with PgLPS. PDLSCs maintained the ability of maturation towards osteoblast/cementoblast phenotype even under exposure to bacterial endotoxin, as shown by the deposition of mineralized matrix in vitro and the expression of three osteogenic gene markers, RUNX2, ALP and OCN. However, previous studies observed that $P$. gingivalis induced a negative effect on osteogenesis, characterized by inhibition of pre-osteoblast differentiation and suppression of bone formation. ${ }^{22,33,34}$ Additionally, P. gingivalis LPS has been shown to decrease the expression of osteogenic gene markers in cementoblasts, ${ }^{15}$ PDL fibroblasts,${ }^{8}$ mouse bone marrow $\mathrm{MSC}^{35}$ and heterogeneous PDLSCs. ${ }^{18}$
Some factors could contribute to the discrepancies in these results such as heterogeneity of the cell source, distinct stages of differentiation and lineage commitment of cells, and experimental conditions. In addition, the method used to purify bacterial products may influence cell behavior. In this study, a commercially available PgLPS was used while other studies purified LPS directly from $P$. gingivalis strain. ${ }^{15,33,34}$ Cell lineage is another important factor; among the cited studies, only one investigated the effects of $P$. gingivalis LPS on PDLSCs. ${ }^{18}$ However, this population was not isolated and highly $\mathrm{CD} 105^{+}$purified periodontal ligament progenitor cells were employed. Since it was already demonstrated that MSCs from PDL harbors a heterogeneous stem-cell-enriched population, ${ }^{32,36,37}$ it is possible that PDLSCs composed by $\mathrm{CD}^{105^{+}}$cell subsets are less susceptible to $P$. gingivalis LPS challenge compared to heterogeneous PDLSC populations. However, further studies are required to elucidate the response of PDLSCs to other $P$. gingivalis virulence factors.

\section{Conclusion}

Our findings provide evidence that $P$. gingivalis LPS induces cytokines' pro-inflammatory response in PDLSCs purified for CD105 marker. However, this response was not able to change the ability of PDLSCs to differentiate towards osteoblast/cementoblast phenotype, suggesting that these cells could develop a mechanism of resistance, which may be very important for periodontal tissue regeneration.

\section{Acknowledgements}

The authors would like to thank São Paulo State Research Foundation (FAPESP, São Paulo, SP, Brazil, grant \#2011/04757-3) for supporting the author through a generous fellowship. The authors report no conflicts of interest related to this study.

\section{References}

1. How KY, Song KP, Chan KG. Porphyromonas gingivalis: an overview of periodontopathic pathogen below the gum line. Front Microbiol. 2016;7:53. http://doi.org/10.3389/fmicb.2016.00053
2. Larsson L, Decker AM, Nibali L, Pilipchuk SP, Berglundh T, Giannobile WV. Regenerative medicine for periodontal and peri-implant diseases. J Dent Res. 2016;95(3):255-66. http://doi.org/10.1177/0022034515618887 
3. Menicanin D, Hynes K, Han J, Gronthos S, Bartold PM. Cementum and periodontal ligament regeneration. Adv Exp Med Biol. 2015;881:207-36. http://doi.org/10.1007/978-3-319-22345-2_12

4. Polimeni G, Xiropaidis AV, Wikesjö UM. Biology and principles of periodontal wound healing/regeneration. Periodontol 2000. 2006;41(1):30-47. http://doi.org/10.1111/j.1600-0757.2006.00157.x

5. Offenbacher S. Periodontal diseases: pathogenesis. Ann Periodontol. 1996;1(1):821-78. http://doi.org/10.1902/annals.1996.1.1.821

6. Pluchino S, Muzio L, Imitola J, Deleidi M, Alfaro-Cervello C, Salani G et al. Persistent inflammation alters the function of the endogenous brain stem cell compartment. Brain. 2008;131(10):2564-78. http://doi.org/10.1093/brain/awn198

7. Goldschmidt-Clermont PJ, Peterson ED. On the memory of a chronic illness. Sci SAGE KE. 2003;2003(45):re8. http://doi.org/10.1126/sageke.2003.45.re8

8. Seo T, Cha S, Kim TI, Lee JS, Woo KM. Porphyromonas gingivalis-derived lipopolysaccharide-mediated activation of MAPK signaling regulates inflammatory response and differentiation in human periodontal ligament fibroblasts. J Microbiol. 2012;50(2):311-9. http://doi.org/10.1007/s12275-012-2146-x

9. Sun Y, Shu R, Li CL, Zhang MZ. Gram-negative periodontal bacteria induce the activation of Toll-like receptors 2 and 4, and cytokine production in human periodontal ligament cells. J Periodontol. 2010;81(10):1488-96. http://doi.org/10.1902/jop.2010.100004

10. Darveau RP, Pham TT, Lemley K, Reife RA, Bainbridge BW, Coats SR et al. Porphyromonas gingivalis lipopolysaccharide contains multiple lipid A species that functionally interact with both toll-like receptors 2 and 4. Infect Immun. 2004;72(9):5041-51. http://doi.org/10.1128/IAI.72.9.5041-5051.2004

11. Silvério KG, Rodrigues TL, Coletta RD, Benevides L, Silva JS, Casati MZ et al. Mesenchymal stem cell properties of periodontal ligament cells from deciduous and permanent teeth. J Periodontol. 2010;81(8):1207-15. http://doi.org/10.1902/jop.2010.090729

12. Krajewski AC, Biessei J, Kunze M, Maersch S, Perabo L, Noack MJ. Influence of lipopolysaccharide and interleukin- 6 on RANKL and OPG expression and release in human periodontal ligament cells. APMIS. 2009;117(10):746-54. http://doi.org/10.1111/j.1600-0463.2009.02532.x

13. Albiero ML, Amorim BR, Martins L, Casati MZ, Sallum EA, Nociti FH Jr et al. Exposure of periodontal ligament progenitor cells to lipopolysaccharide from Escherichia coli changes osteoblast differentiation pattern. J Appl Oral Sci. 2015;23(2):145-52. http://doi.org/10.1590/1678-775720140334
14. Zhao Q, Gong P, Tan Z, Yang X. Differentiation control of transplanted mesenchymal stem cells (MSCs): a new possible strategy to promote periodontal regeneration. Med Hypotheses. 2008;70(5):944-7. http://doi.org/10.1016/j.mehy.2007.09.013

15. Nociti FH Jr., Foster BL, Barros SP, Darveau RP, Somerman MJ. Cementoblast gene expression is regulated by Porphyromonas gingivalis lipopolysaccharide partially via toll-like receptor-4/MD-2. J Dent Res. 2004;83(8):602-7. http://doi.org/10.1177/154405910408300804

16. Morsczeck C, Gotz W, Schierholz J, Zeilhofer F, Kuhn U, Mohl C et al. Isolation of precursor cells (PCs) from human dental follicle of wisdom teeth. Matrix Biol. 2005;24(2):155-65. http://doi.org/10.1016/j.matbio.2004.12.004

17. Nagatomo K, Komaki M, Sekiya I, Sakaguchi Y, Noguchi K, Oda $S$ et al. Stem cell properties of human periodontal ligament cells. J Periodontal Res. 2006;41(4):303-10. http://doi.org/10.1111/j.1600-0765.2006.00870.x

18. Kato H, Taguchi Y, Tominaga K, Umeda M, Tanaka A. Porphyromonas gingivalis LPS inhibits osteoblastic differentiation and promotes pro-inflammatory cytokine production in human periodontal ligament stem cells. Arch Oral Biol. 2014;59(2):167-75. http://doi.org/10.1016/j.archoralbio.2013.11.008

19. Mafi P, Hindocha S, Mafi R, Griffin M, Khan WS. Adult mesenchymal stem cells and cell surface characterization - a systematic review of the literature. The open orthopaedics journal. 2011;5(Suppl 2):253-60. http://doi.org/10.2174/1874325001105010253

20. Medzhitov R, Preston-Hurlburt P, Janeway CA Jr. A human homologue of the Drosophila Toll protein signals activation of adaptive immunity. Nature. 1997;388(6640):394-7. http://doi.org/10.1038/41131

21. Hatakeyama J, Tamai R, Sugiyama A, Akashi S, Sugawara S, Takada H. Contrasting responses of human gingival and periodontal ligament fibroblasts to bacterial cell-surface components through the CD14/Toll-like receptor system. Oral Microbiol Immunol. 2003;18(1):14-23. http://doi.org/10.1034/j.1399-302X.2003.180103.x

22. Kadono H, Kido J, Kataoka M, Yamauchi N, Nagata T. Inhibition of osteoblastic cell differentiation by lipopolysaccharide extract from Porphyromonas gingivalis. Infect Immun. 1999;67(6):2841-6.

23. Yamamoto T, Kita M, Oseko F, Nakamura T, Imanishi J, Kanamura N. Cytokine production in human periodontal ligament cells stimulated with Porphyromonas gingivalis. J Periodontal Res. 2006;41(6):554-9. http://doi.org/10.1111/j.1600-0765.2006.00905.x

24. Lisignoli G, Cristino S, Toneguzzi S, Grassi F, Piacentini A, Cavallo $C$ et al. IL1beta and TNFalpha differently modulate CXCL13 chemokine in stromal cells and osteoblasts isolated from osteoarthritis patients: evidence of changes associated to cell maturation. Exp Gerontol. 2004;39(4):659-65. http://doi.org/10.1016/j.exger.2003.09.030 
25. Yamaji Y, Kubota T, Sasaguri K, Sato S, Suzuki Y, Kumada H et al. Inflammatory cytokine gene expression in human periodontal ligament fibroblasts stimulated with bacterial lipopolysaccharides. Infect Immun. 1995;63(9):3576-81.

26. Diya Zhang, Lili Chen, Shenglai Li, Zhiyuan Gu, Jie Yan. Lipopolysaccharide (LPS) of Porphyromonas gingivalis induces IL-1beta, TNF-alpha and IL-6 production by THP-1 cells in a way different from that of Escherichia coli LPS. Innate Immun. 2008;14(2):99-107. http://doi.org/10.1177/1753425907088244

27. Kim SH, Kim YS, Lee SY, Kim KH, Lee YM, Kim WK et al. Gene expression profile in mesenchymal stem cells derived from dental tissues and bone marrow. J Periodontal Implant Sci. 2011;41(4):192-200. http://doi.org/10.5051/jpis.2011.41.4.192

28. Hidaka T, Nagasawa T, Shirai K, Kado T, Furuichi Y. FGF-2 induces proliferation of human periodontal ligament cells and maintains differentiation potentials of STRO-1(+)/CD146(+) periodontal ligament cells. Arch Oral Biol. 2012;57(6):830-40. http://doi.org/10.1016/j.archoralbio.2011.12.003

29. Tomic S, Djokic J, Vasilijic S, Vucevic D, Todorovic V, Supic $\mathrm{G}$ et al. Immunomodulatory properties of mesenchymal stem cells derived from dental pulp and dental follicle are susceptible to activation by toll-like receptor agonists. Stem Cells Dev. 2011;20(4):695-708. http://doi.org/10.1089/scd.2010.0145

30. Kong Q, Liu L, Huang Y, Zhang F, Wei X, Ling J. The effect of octamer-binding transcription factor 4B1 on microRNA signals in human dental pulp cells with inflammatory response. J Endod. 2014;40(1):101-8. http://doi.org/10.1016/j.joen.2013.09.030
31. Pittenger MF, Mackay AM, Beck SC, Jaiswal RK, Douglas R, Mosca JD et al. Multilineage potential of adult human mesenchymal stem cells. Science. 1999;284(5411):143-7. http://doi.org/10.1126/science.284.5411.143

32. Seo BM, Miura M, Gronthos S, Bartold PM, Batouli $\mathrm{S}$, Brahim J et al. Investigation of multipotent postnatal stem cells from human periodontal ligament. Lancet. 2004;364(9429):149-55. http://doi.org/10.1016/S0140-6736(04)16627-0

33. Loomer PM, Ellen RP, Tenenbaum HC. Characterization of inhibitory effects of suspected periodontopathogens on osteogenesis in vitro. Infect Immun. 1995;63(9):3287-96.

34. Loomer PM, Sigusch B, Sukhu B, Ellen RP, Tenenbaum HC. Direct effects of metabolic products and sonicated extracts of Porphyromonas gingivalis 2561 on osteogenesis in vitro. Infect Immun. 1994;62(4):1289-97.

35. Xing Q, Ye Q, Fan M, Zhou Y, Xu Q, Sandham A.

Porphyromonas gingivalis lipopolysaccharide inhibits the osteoblastic differentiation of preosteoblasts by activating Notch1 signaling. J Cell Physiol. 2010;225(1):106-14. http://doi.org/10.1002/jcp.22201

36. Sununliganon L, Singhatanadgit W. Highly osteogenic PDL stem cell clones specifically express elevated levels of ICAM1, ITGB1 and TERT. Cytotechnology. 2012;64(1):53-63. http://doi.org/10.1007/s10616-011-9390-5

37. Saito MT, Salmon CR, Amorim BR, Ambrosano GM, Casati MZ, Sallum EA et al. Characterization of highly osteoblast/cementoblast cell clones from a CD105-enriched periodontal ligament progenitor cell population. J Periodontol. 2014;85(6):e205-11. http://doi.org/10.1902/jop.2014.130461 